\title{
Brain Aging: Impaired Coding of Novel Environmental Cues
}

\author{
Heikki Tanila, ${ }^{1}$ Perttu Sipilä, ${ }^{1}$ Matthew Shapiro, ${ }^{2}$ and Howard Eichenbaum ${ }^{3}$ \\ ${ }^{1}$ Department of Neuroscience and Neurology, University of Kuopio, 70211 Kuopio, Finland, 2Department of Psychology, \\ McGill University, Montreal, Quebec QC H3A 1B1, Canada, and ${ }^{3}$ Department of Psychology, Boston University, Boston, \\ Massachusetts 02215
}

Studies of the spatial memory capacities of aged animals usually focus on performance during the learning of new environments. By contrast, efforts to characterize age-related alterations in spatial firing information processing by hippocampal neurons typically use an environment that is highly familiar to the animals. In the present study we compared the firing properties of hippocampal neurons in young adult and aged rats as they acquired spatial information about new environmental cues. Hippocampal complex spike cells were recorded while rats performed a radial arm maze task in a familiar environment and then recorded again after many of the spatial cues were changed. After the change in the environment, in aged rats $35-42 \%$ of place fields retained their original shape and loca- tion with respect to the maze center, although they usually rotated to another arm. By contrast, all place fields in young animals either disappeared or appeared in a new location. Some of the new place fields appeared in the new environment during the first $5 \mathrm{~min}$ of exploration, whereas others needed more than 30 min to develop fully. In the familiar environment spatial selectivity of place cells was similar in young and aged rats. By contrast, when rats were placed into a new environment, spatial selectivity decreased considerably in aged memory-impaired rats compared with that of young rats and aged rats with intact memory performance.

Key words: aging; hippocampus; place field; spatial learning; electrophysiology; rat
The hippocampus plays a critical role in spatial learning in rats (Morris et al., 1982). Correspondingly, the activity of hippocampal complex spike cells (Ranck, 1973) correlates strongly with the location of the rat in the testing environment during exploratory behavior such that the firing of so-called "place cells" is often restricted to one or a few "place fields" within the environment (O'Keefe and Conway, 1978). Studies aimed to elucidate the nature of cognitive decline in aging have recently exploited these findings to develop animal models of age-related cognitive decline. Aged rats are impaired in spatial learning, although the severity of the deficit is highly variable (Barnes, 1988, 1994; DeToledo-Morrell et al., 1988; Gage et al., 1988; Markowska et al., 1989; Rapp and Amaral, 1992; Gallagher and Nicolle, 1993; Rapp and Heindel, 1994). Previous studies on place cells in aged rats have reported that their spatial specificity may decrease with age (Barnes et al., 1983), but other recent studies, including our own, have failed to confirm any clear association between place field specificity and impaired spatial learning in aged animals (Mizumori et al., 1996; Tanila et al., 1997). However, all of the electrophysiological studies were conducted using environments that were highly familiar to the animals, whereas virtually all the studies that demonstrate the age-related spatial impairment focus on learning new spatial environments. The present study was designed to record the activity of hippocampal place cells in a situation comparable with those typically used in learning exper-

Received Feb. 10, 1997; revised April 9, 1997; accepted April 11, 1997

This work was supported by the National Institute on Aging, National Institute of Mental Health, Academy of Finland, Medical Research Council of Canada, National Science and Engineering Research Center of Canada, and McGill University for salary support of M.S. during his sabbatical. Preparation of histological material for confirmation of electrode locations was performed by J. Niedermair.

Correspondence should be addressed to Dr. Howard Eichenbaum, Laboratory of Cognitive Neorobiology, Department of Psychology, Boston University, 64 Cummington Street, Boston, MA 02215.

Copyright (C) 1997 Society for Neuroscience $\quad 0270-6474 / 97 / 175167-08 \$ 05.00 / 0$ iments. Therefore, we recorded hippocampal unit activity in young and aged rats as they explored an environment characterized by novel spatial cues. In young rats, sometimes new place fields seem to appear almost instantly in a new environment (Hill, 1978), but there is also evidence that place fields gradually "focus," or increase their spatial specificity, within the first 30 min of exploration in a new environment (Austin et al., 1993; Wilson and McNaughton, 1993). We expected that the rate of focusing would be slower in those aged rats that are impaired in spatial memory capacity.

Recording place cells in a new environment involves an inherent technical obstacle in that: (1) old rats tend to explore new environments with some hesitation; and (2) old rats fail to explore them sufficiently even when they are motivated by hunger and food is dispersed in the environment (Spangler et al., 1989). Yet free voluntary movement has been shown to be necessary for place-specific activity by CA1 pyramidal cells (Foster et al., 1989), and movement variables such as speed and direction further modify the firing rate of these place cells (Wiener et al., 1989). We used two strategies to ensure adequate voluntary movement in the new environment. First, the animals were pretrained on a memory task in two different environments, and second, highly motivating electrical stimulation of the lateral hypothalamus was used as a reinforcement as an alternative to food rewards. Second, we maintained the identical general task demands but removed familiar spatial cues and introduced new ones into the environment. Using these procedures we were able to hold constant the extent and type of voluntary movements in young and aged rats and to examine changes in spatial specificity associated with experience learning the new environmental cues.

\section{MATERIALS AND METHODS}

Subjects. Three young (4-6 months, 35-450 gm at the beginning of the recordings) and four aged (25-29 months, 450-600 gm) male Long- 
FAMILIAR

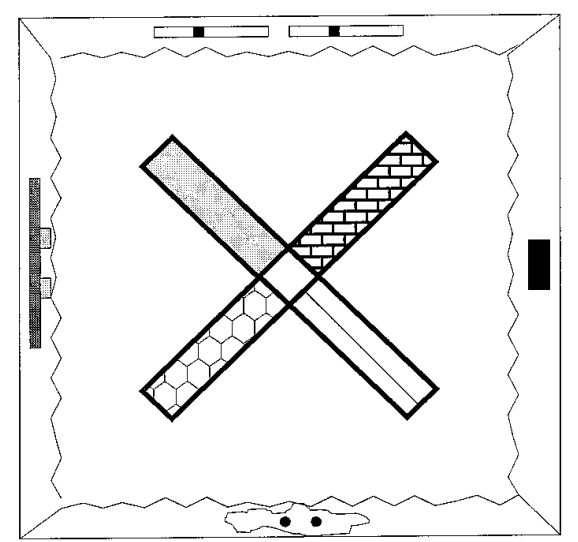

NEW 1

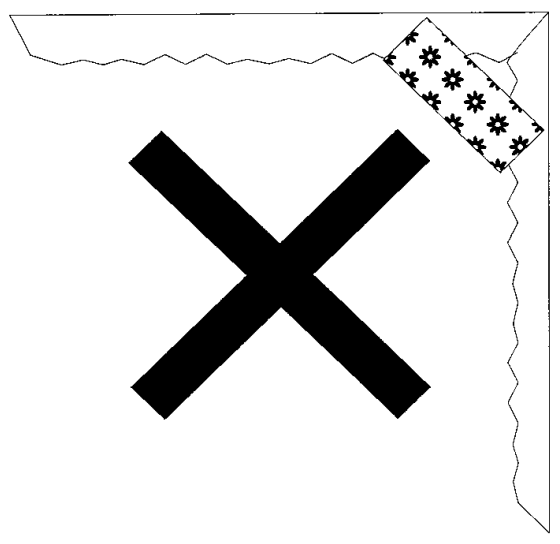

NEW 2

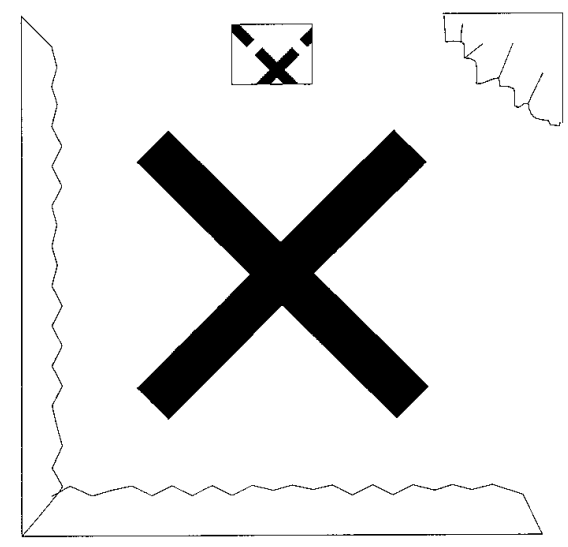

Figure 1. Schematic illustration of the recording environments. In the familiar environment the maze was screened from the rest of room by black curtains ( $185 \mathrm{~cm}$ wide) extending from the floor to $30 \mathrm{~cm}$ from the ceiling (curtains are white for clarity). On the four walls of the curtain were hanging clearly distinguishable landmark cards. The maze was covered with insertable surfaces differing in texture and smell. In new environment 1 ( $N E W 1)$ a colorful pillowcase was a prominent landmark in one corner (top right corner). The curtains were drawn from two walls, revealing a view to the experimenter with a computer and an instrument rack. In new environment 2 (NEW 2) only blank white laboratory walls were visible through the openings in the curtained enclosure. A white and green plastic bag hanging from the ceiling was the only prominent landmark. The mazes were covered with odorless wooden black surfaces in both new environments.

Evans rats served as subjects. Rats were the same that were used in the study described in our accompanying paper (Tanila et al., 1997). The animals were individually housed from the beginning of pretraining, maintained on a $12 \mathrm{hr}$ light/dark cycle, and given ad libitum access to water. Food consumption was controlled to prevent weight increase during the experiment. The health of the aged rats was followed by monitoring their food and water consumption and general health. When the brains of the rats were removed for histological verification of the electrode marks, all brains were carefully inspected for tumors. The aged rats were prescreened by M. Gallagher (Department of Psychology, University of North Carolina, Chapel Hill, NC) in the Morris water maze. Two of the aged rats had their learning indices (Gallagher et al., 1993) within the range of young rats and were therefore considered memoryintact. Two of the aged rats that had their learning indices outside the range of young rats were considered memory-impaired. The experimenter conducting the recordings was blind to the learning indices of the aged rats.

Electrodes, surgery, and data acquisition. The techniques are been described in detailed in our accompanying paper (Tanila et al., 1997) and are only briefly mentioned here. The recording electrodes were tetrodes made of $30 \mu \mathrm{m}$ Formvar-coated nichrome wires, and the stimulation electrodes were a twisted pair of $100 \mu \mathrm{m}$ Teflon-coated stainless steel wires.

The animals were anesthetized with ketamine $(50 \mathrm{mg} / \mathrm{kg})$ and xylazine $(7.5 \mathrm{mg} / \mathrm{kg}, \mathrm{i} . \mathrm{m}$.), and electrodes were surgically implanted at the following coordinates: the stimulation electrodes aimed at the lateral hypothalamus $0.5 \mathrm{~mm}$ posterior and 1.5 lateral to bregma and $7.7 \mathrm{~mm}$ below the pial surface (tip of the longer wire); the tetrode aimed at dorsal CA1 3.3 $\mathrm{mm}$ posterior and 2.0 lateral to bregma and $1.5-1.9 \mathrm{~mm}$ below the pial surface. The microdrive and connector were attached to the surface of the skull by dental cement and four stainless steel screws, two of which served as the electrical ground. The data were digitized and analyzed using Enhanced Discovery and Autocut software (DataWave Technologies Inc.). The position of the rat in the maze was determined by a video camera following system (DataWave Technologies) that tracked two incandescent light bulbs mounted on the head stage assembly. Location was digitized in the form of $x$ - and $y$-coordinate pairs at the rate of $60 \mathrm{~Hz}$. Only complex spike cells (Ranck, 1973) with a duration of the negative spike of more than $300 \mu \mathrm{sec}$ and a signal-to-noise ratio of $>3: 1$ were sampled for this study.

Behavioral apparatus. In the course of the study the rats encountered four different environments. Common to all was a four-arm radial maze elevated $70 \mathrm{~cm}$ above the floor. The maze had a central octagonal platform $12 \mathrm{~cm}$ on each side and arms that were $45 \mathrm{~cm}$ long and $10 \mathrm{~cm}$ wide with 6-cm-deep angled sides at the end of each arm. Shaping took place in the $4 \times 6 \mathrm{~m}$ laboratory workshop, which was separate from the room used for all subsequent sessions. In this environment the maze arms were covered with odorized black surfaces. Subsequent training and recording took place in a quiet, dimly lit $2.5 \times 3.5 \mathrm{~m}$ room. The maze was illuminated by four $12 \mathrm{~V}$ DC lights located symmetrically on a ceiling panel above the maze. White noise was delivered by two speakers on the ceiling panel in the familiar environment but was turned off in the new environments. The recording room was arranged in three different ways to create three distinct environments (Fig. 1). In the first of these arrangements, hereafter referred to as the "familiar" environment, the arms of the maze were covered with surfaces that were composed of coarse plastic mesh, sandpaper, fine wire mesh, and coarsely ridged rubber; these contained distinct common food odors (anise, coconut, strawberry, and peppermint) sprayed on each arm. In other arrangements of the room, hereafter referred to as the "new" environments, the maze was covered with black odorless surfaces. In the familiar environment the maze was surrounded by four $175-\mathrm{cm}$-wide black curtains from which hung 30 - to $90-\mathrm{cm}$-wide, complex bright patterns. In one of the new environments two of the curtains were opened wide to reveal a view of the experimenter and the recording instruments. A brightly colored pillowcase with a flower pattern was placed on the closed corner. In a second new environment, the remaining two curtains were drawn together to form a column at one corner. The opened curtains revealed a view of blank white laboratory walls. As a separate cue, a white and green plastic bag was hung at one of the openings (Fig. 1).

Behavioral procedures. All rats were first trained on a win-shift working memory task using a four arm radial maze with chocolate milk as the reinforcement. After 2-4 weeks of daily training, when the rats performed the task with $<10 \%$ reentries to visited arms, they were tested twice in the familiar environment and then operated for electrode im-

Table 1. Changes in place fields in response to new environment

\begin{tabular}{llcl} 
Change & Young & Aged intact & Aged impaired \\
\hline No change & $0(0 \%)$ & $3(15 \%)$ & $3(25 \%)$ \\
Rotation & $0(0 \%)$ & $4(20 \%)$ & $2(17 \%)$ \\
Disappearance & $9(50 \%)$ & $2(10 \%)$ & $3(25 \%)$ \\
New field(s) & $8(44 \%)$ & $11(55 \%)$ & $3(25 \%)$ \\
Mixed response & $1(6 \%)$ & $0(0 \%)$ & $1(8 \%)$
\end{tabular}




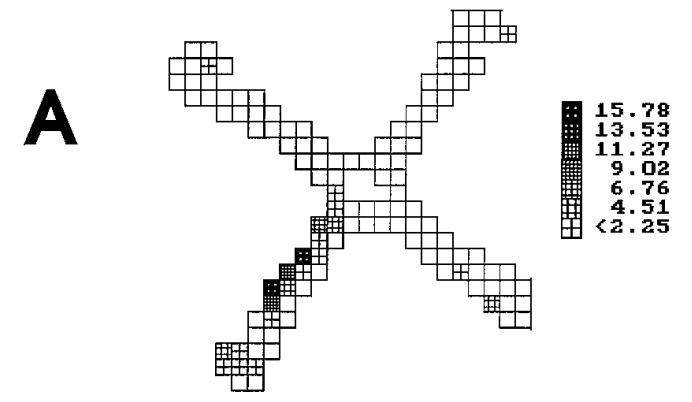

\section{$5 \min$}

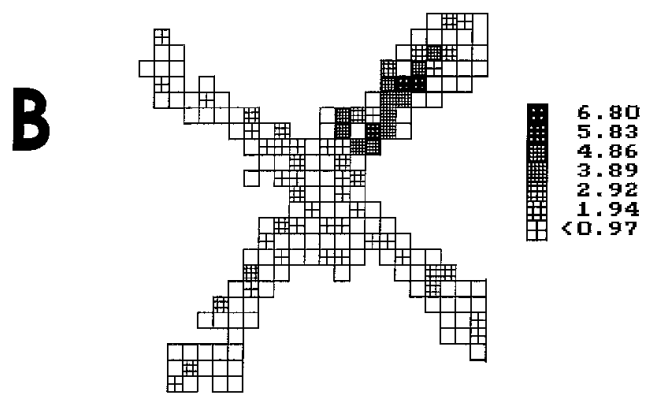

$10 \min$

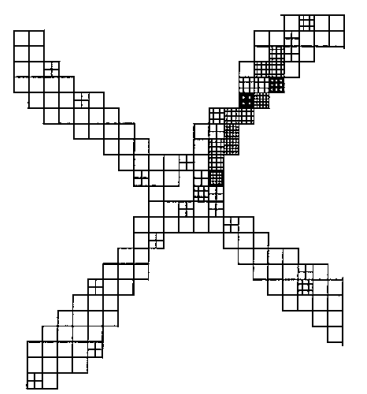

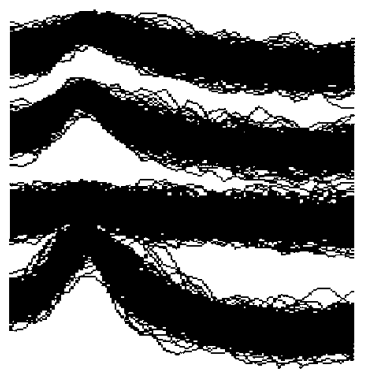

$20 \min$

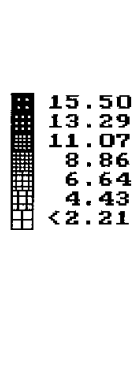

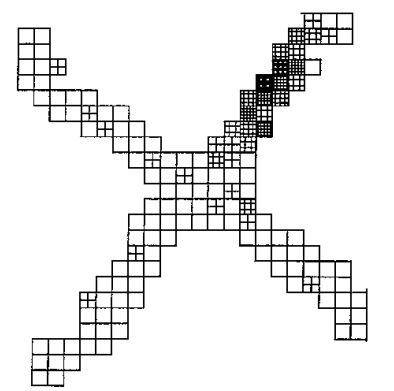

Figure 2. Raw firing rate maps recorded from an aged memory-intact rat. $A$, Distribution of firing rates in the familiar environment. $B$, Firing rate maps in the new environment for the first, second, and fourth 5 min trials. The place field rotates $180^{\circ}$ with the change of the environment. Spatial selectivities are: familiar environment, 20.7; and new environment after $5 \mathrm{~min}, 9.4$; after $10 \mathrm{~min}, 16.6$; and after $20 \mathrm{~min}$, 16.4. Note that the gratings are relative, so that the pixel with the highest firing rate in each icon is black. The corresponding firing rates are shown by the numbers to the right of each icon. $C$, Waveform of the neuron recorded with a tetrode. Each curve represents superimposed waveforms recorded from each one of the four tips of the electrode.

plantation. After recovery the rats were first trained to visit the ends of the arms and to return to the center by rewarding them with electrical stimulation of the lateral hypothalamus ( 0.5 trains/ $/ \mathrm{sec}$ of $0.5 \mathrm{msec}$ pulses at $100 \mathrm{~Hz}, 60-200 \mu \mathrm{A})$. When a stimulus current was found that kept the rat constantly moving, the win-shift working memory task was reintroduced. Training was maintained while the tetrode was slowly moved toward CA1 over approximately 3 weeks. The rats typically solved the working memory requirement by adopting a stereotypic rotation of adjacent arm selections, occasionally changing the direction of rotation. As evident in the stereotypic arm choice pattern, the rats may not have used spatial memory to solve the task.

When complex spike cells were encountered, the waveforms were saved, and the rat was returned to its home cage. On the next day, if the waveforms were the same a recording session was run. The first trial took place in the familiar environment and lasted $5 \mathrm{~min}$. Afterward the rat was placed into a closed round bucket and carried a distance of at least $30 \mathrm{~m}$, entering different laboratory rooms and opening and closing several doors on the way. Finally the rat was carried back into the recording room and released into the maze to perform the working memory task in the new environment. Four 5 min trials were run with intervening $5 \mathrm{~min}$ pauses, during which the rat was put into the closed bucket. After the fourth trial the rat was allowed to explore the new environment freely for 30 min without performing the task, and then a final 5 min trial was run. Then the rat was carried into the adjacent room inside the bucket, and the recording room was reconfigured into its original, familiar arrangement. The rat was again carried around the laboratory to disorient it, and then another 5 min recording was taken as the rat performed the working memory task. For each of the trials, the start arm was varied according to a pseudorandom and balanced sequence.

Because recordings from one of the aged memory-impaired rats was determined to be from CA3 instead of CA1, one young and one aged memory-intact rat were later exposed to the second new environment when their electrodes had reached the hilar CA3. During the 1 month period between exposure to the initial new environment and the second one, the rats were repeatedly run in the familiar environment.

Histology. The locations of the electrode tips at the end of the recordings were marked by passing positive current to deposit small amounts of iron into the tissue, which was later visualized by Prussian blue reaction in histological slices. The details of perfusion, slice preparation, and determination of the recording sites are described in detail in our accompanying paper (Tanila et al., 1997).

Data analysis. To confirm that our training methods resulted in equivalent voluntary movement among the groups, the running speeds were computed for each consecutive pair of video tracking coordinates, and the average speed of movement was calculated for each subject and then compared across groups and environments with a two-way ANOVA.

The spatial distribution of firing rates over the maze area was calculated by first dividing the maze into $3 \times 3 \mathrm{~cm}$ pixels, resulting in a $28 \times$ 28 grid. The total number of spikes associated with each pixel was divided by the total time spent in that pixel. Time and spike counts were included only when the rat was moving at least $2 \mathrm{~cm} / \mathrm{sec}$. A place field was defined as an area of at least three adjacent pixels each having a firing rate at least three times the grand mean rate (total number of spikes/total time spent moving in the maze), and a mean within-field (infield) firing rate at least five times the overall mean firing rate for that neuron.

For all cells with defined place fields the following parameters were calculated for each $5 \mathrm{~min}$ trial: number of fields, grand mean rate (total number of spikes/total time), mean infield firing rate, mean place field area (in pixels), and spatial selectivity. Spatial selectivity was calculated as the infield/out-of-field firing rate ratio. In the case of multiple fields, an average was calculated except for spatial selectivity; in that case the place field with the highest infield/outfield ratio was taken to represent the whole cell. Because some cells had almost no firing outside the place fields, resulting in almost infinite ratios, a cutoff for the ratio was set to 500 . For each cell the average of each parameter was calculated both for the familiar environment (two trials) and for the new environment (five 


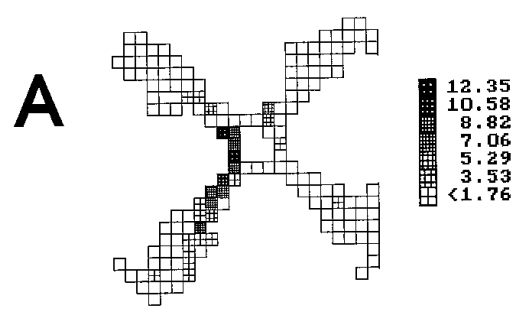

$5 \min$

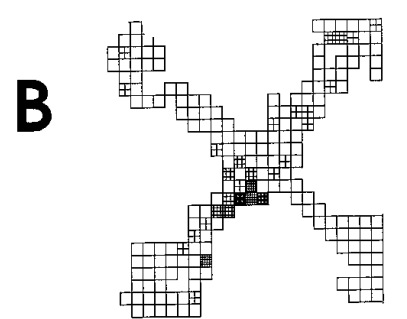

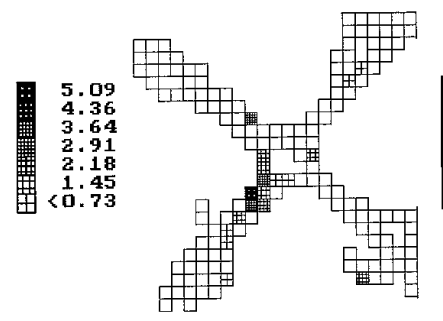
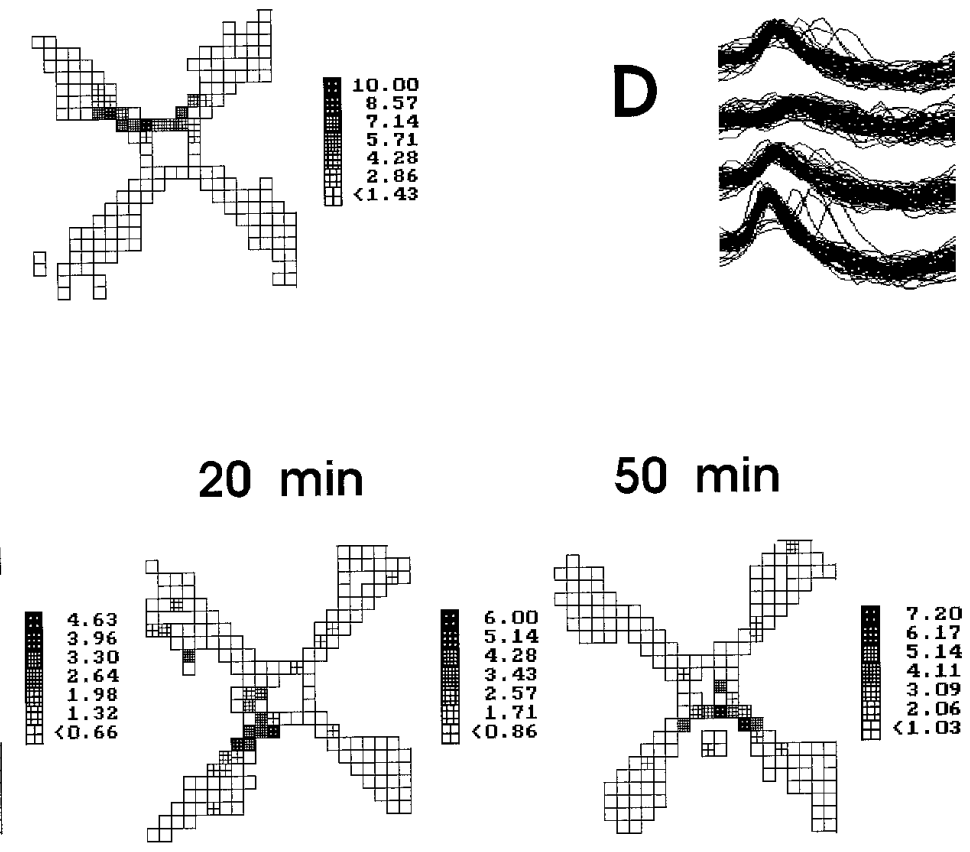

Figure 3. Raw firing rate maps recorded from an aged memory-impaired rat. $A$, Familiar environment. $B$, First, second, fourth, and fifth 5 min trials in the new environment. $C$, Return to the familiar environment. $D$, Waveform of the neuron recorded with a tetrode. After exposure to the new environment the shape of the place field slightly changes, but the location remains in the same position with respect to the maze and the room. After the 30 min exploration of the new environment, the place field unexpectedly rotates $90^{\circ}$ counterclockwise $(50 \mathrm{~min})$. After return of the rat to the familiar environment the place field appeared rotated $90^{\circ}$ clockwise compared with its original orientation.

trials). Comparisons between the experimental groups were then carried out using ANOVA with repeated measures, followed by Duncan's post hoc tests.

Comparisons of the spatial distributions of firing between trials were made by calculating cross-correlations between the firing rate maps of each trial. In these correlations a smoothing procedure was used such that for each pixel with a firing rate above zero, firing rates of those pixels that shared a side with the central pixel were incremented by $50 \%$ of the firing rate of the central pixel; similarly, firing rates of those pixels that only shared a corner with the central pixel were incremented by $30 \%$ of the firing rate of the central pixel. Cross-correlations were calculated between the first trial in the familiar environment and the first trial in the new environment to determine whether there was a remapping. The average of all cross-correlations between the familiar and each repetition of the new environment was taken as a measure of the stability of the new fields. In each case the correlations were computed for 90,180 , and $270^{\circ}$ rotations of the new environment firing map to test whether changes could be accounted for by a rotation of the spatial representation. Comparisons between groups were made by calculating a Pearson correlation coefficient for each cell and then comparing $r$ values among the experimental groups using one-way ANOVA with Duncan's post hoc tests.

\section{RESULTS}

\section{Behavioral results}

The average speed of movement in the familiar environment was $5.4 \mathrm{~cm} / \mathrm{sec}$ in young rats, $4.5 \mathrm{~cm} / \mathrm{sec}$ in aged memory-intact rats, and $4.3 \mathrm{~cm} / \mathrm{sec}$ in aged memory-impaired rats. In the new environment the values were $5.3 \mathrm{~cm} / \mathrm{sec}$ in young rats, $4.0 \mathrm{~cm} / \mathrm{sec}$ in aged memory-intact rats, and $4.3 \mathrm{~cm} / \mathrm{sec}$ in aged memoryimpaired rats. ANOVA did not indicate significant differences between the experimental groups [ANOVA, $F_{(2,6)}=0.99 ; p>$ $0.40]$, the environments $\left[F_{(1,6)}=0.58 ; p>0.40\right]$, or the interaction between the groups and the environments.

\section{Electrophysiological data}

The sample of neurons consisted of 35 CA1 complex spike cells (young rats, 13; aged intact, 14; and aged impaired, 8), and 15
CA3 complex spike cells (young, 5; aged intact, 6; and aged impaired, 4). Cells from those two hippocampal layers did not differ on any measure, so the data were pooled.

When all cells that had detectable place fields during any 5 min recording period were included, there was a considerable difference in the proportion of silent cells (grand mean rate, $\leq 0.02 / \mathrm{sec}$ ) between the age groups. In young rats, $33.3 \%$ of cells that had a place field in the familiar environment were silent in the new environment, and conversely, $33.3 \%$ of those cells that had a detectable field in the new environment were silent in the familiar one. Aged memory-intact rats had no silent cells in the familiar environment, but $10 \%$ of their cells turned off in the new environment. Aged memory-impaired rats had no silent cells in either environment. Silent cells excluded, the grand mean rate of the remaining cells did not differ between the experimental groups in either the familiar [ANOVA, $F_{(2,43)}=2.2 ; p>0.10$ ] or new [ANOVA, $F_{(2,42)}=1.7 ; p>0.10$ ] environment.

\section{Changes in spatial representations in the new environment}

In response to changes in the environment, the place fields: (1) remained in the same maze location, (2) maintained their location with respect to the maze center but rotated onto a different maze arm, or (3) disappeared, or (4) new fields appeared. In those cases in which a new field appeared in the new environment, the cell had either been silent in the familiar environment or had had a different place field that was replaced by the new one. Some mixed responses were also observed, such as when one component (subfield) of the place field remained or rotated and another subfield disappeared.

Table 1 summarizes the changes in place fields in response to the new environment. The distribution of responses differed significantly between the young rats and both groups of aged rats $\left[\chi^{2}\right.$ $(8)=15.9 ; p<0.04]$. Notably all cells recorded in young rats 

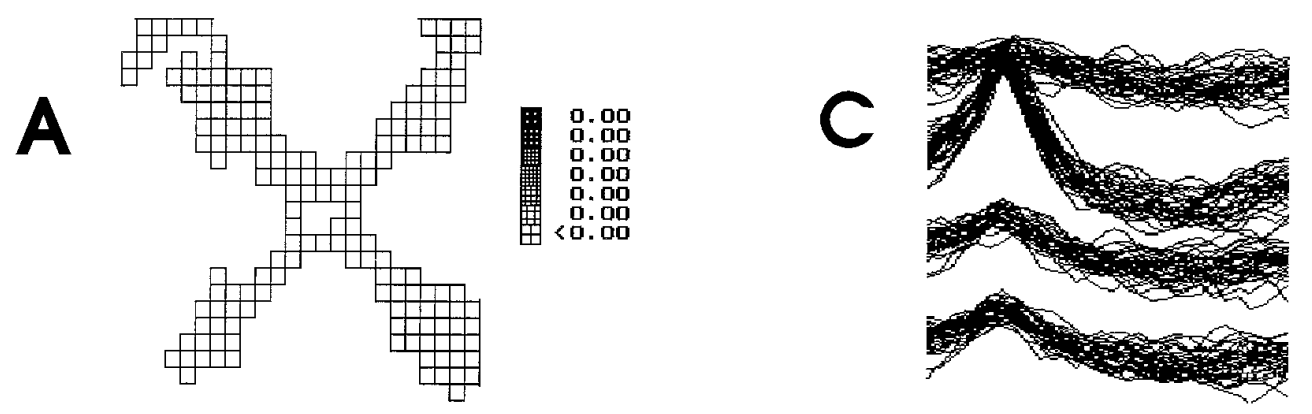

\section{5 min}

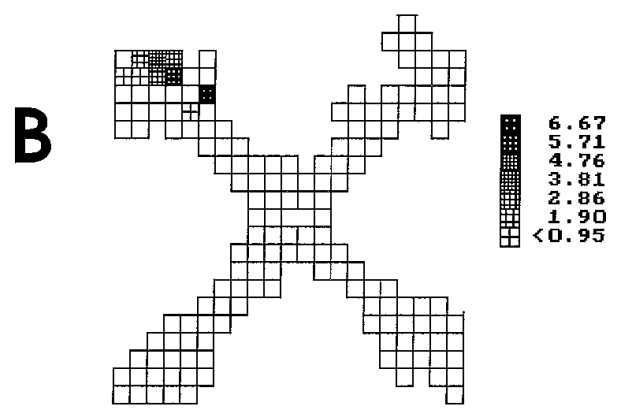

$10 \mathrm{~min}$

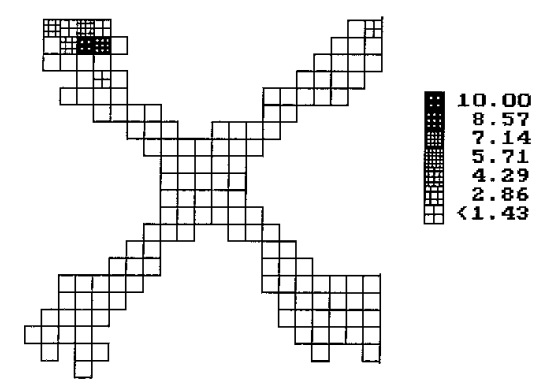

$20 \mathrm{~min}$

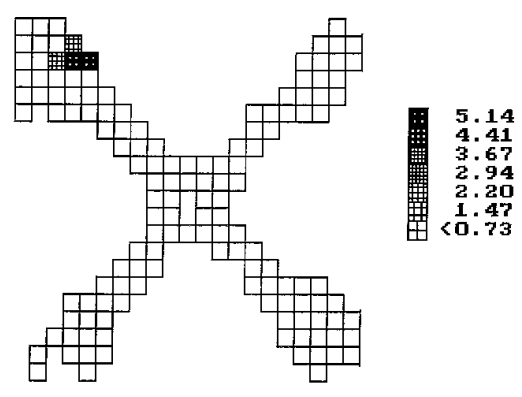

Figure 4. Raw firing rate maps recorded from a young rat. The neuron does not fire at all in the familiar environment $(A)$, but a clear place field appears during the first $5 \mathrm{~min}$ trial in the new environment. Spatial selectivity of the place field increased during the following 15 min exposure to the new environment, however (spatial selectivities: $5 \mathrm{~min}, 134.3 ; 10 \mathrm{~min}, 345.2$; and $20 \mathrm{~min},>500$ ). Other explanations are as in Figure 2.

showed qualitative changes in the spatial representation, either in the form of a disappearance of the place fields or the appearance of new place fields. By contrast, a substantial fraction of the cells of aged rats from both subgroups had fields in the new environment that stayed in the same axial position either within the same arm or rotated to another arm. This finding was confirmed by the cross-correlations between the firing maps of first recording in the familiar environment and the first trial in the new environment. For these comparisons the highest correlation across the four rotations of the new environment was used. The average correlation coefficients significantly differed among the groups [young, $r=0.15$; aged memory-intact, $r=0.34$; and aged memoryimpaired $r=0.38$; ANOVA, $\left.F_{(2,47)}=3.44 ; p=0.04\right]$, and the young animals differed from both groups of aged animals $(p<$ 0.05 , Duncan's tests). Figure 2 shows a typical example of a field that retained its shape and axial location but rotated with respect to the room coordinates. Figure 3 shows another example in which the fields in the new environment initially remained in the same position as in the familiar environment but later rotated during another trial in the new environment.

All rats had cells with place fields in the familiar environment that disappeared as the rats were brought to the new environment. For most of these cells the place fields disappeared later during the experiment and did not reappear even when the rat returned to the familiar environment. Instead these cells either became silent, that is, only occasionally fired (grand mean rate, $<0.02$ spikes/sec), or became noisy, that is, had a grand mean rate of $>0.02$ spikes/sec but without a place field according to the criteria. Among those cells for which place fields disappeared, four of nine in young rats and two of two in aged memory-intact rats became "silent," whereas all three of such cells in aged memoryimpaired rats became noisy.

Cells that had place fields in the new environment that could not be a result of any rotation of the spatial firing map could also be further divided into two types. In the first type, the new place field(s) appeared within the first 5 min trial in the new environment (Fig. 4). Usually these cells had one pattern of place fields in the familiar environment and another pattern in the new environment. The second type of these cells were silent in the familiar environment and gradually became more active in the new environment, eventually developing a circumscribed place field (Fig. 5 ). Notably, in young rats, $50 \%$ of the cells with new place fields were silent in the familiar environment, whereas $10 \%$ of such cells were observed in aged memory-intact animals, and none were observed in aged memory-impaired animals.

\section{Changes in spatial selectivity of place fields in the new environment}

During the first trial in the familiar environment, the groups did not differ in spatial selectivity (see above). However, when the rats were brought to the new environment, mean spatial selectivity decreased during the first $5 \mathrm{~min}$ trial in young and aged memoryimpaired rats but not in the aged memory-intact group (Figs. $2 B$, 6). Spatial selectivity increased significantly during the five recording sessions in the new environment [repeated measures ANOVA, $F_{(3,75)}=2.77 ; p<0.05$ for the effect of the trial]. Furthermore, an interesting additional observation came from the comparisons of spatial selectivity between familiar and new envi- 

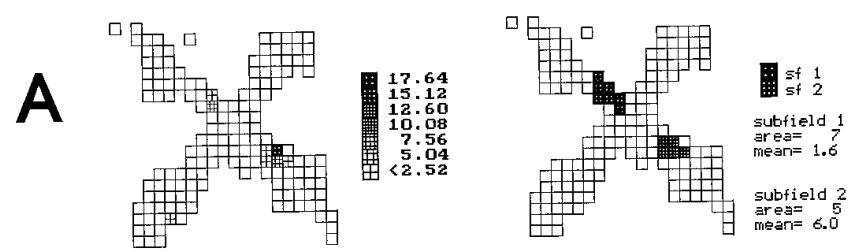

$15 \min$
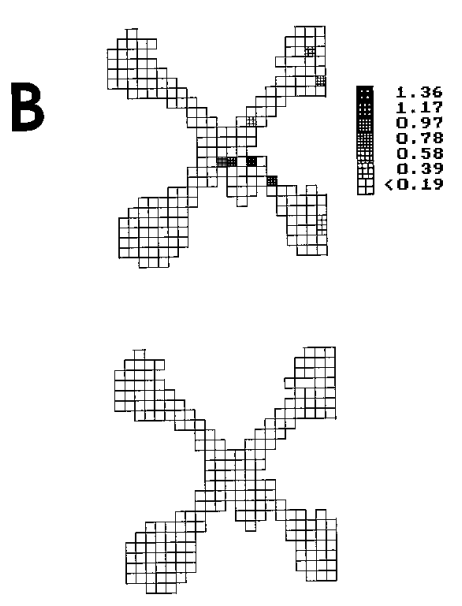

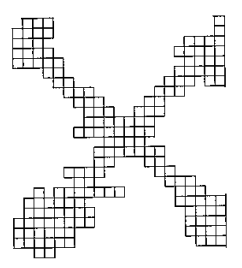

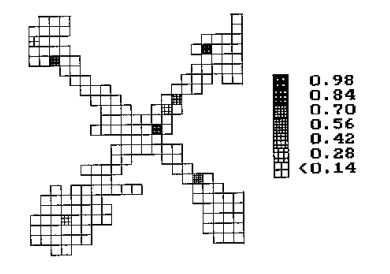

$5 \min$

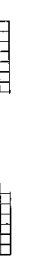

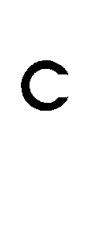
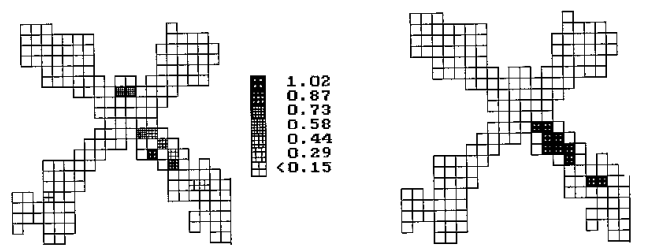

: $s f 1$

subtield 1
artea= 10
mean= $=0.38$

\section{$20 \mathrm{~min}$}
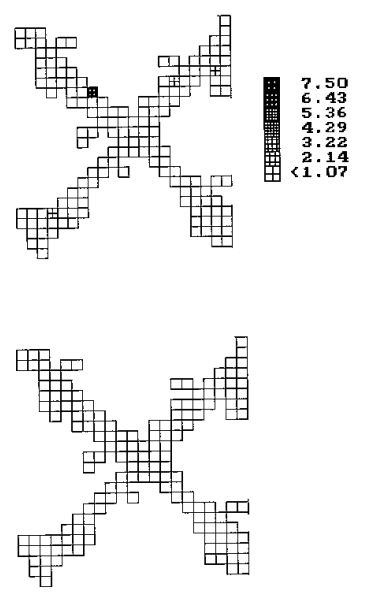

$50 \min$
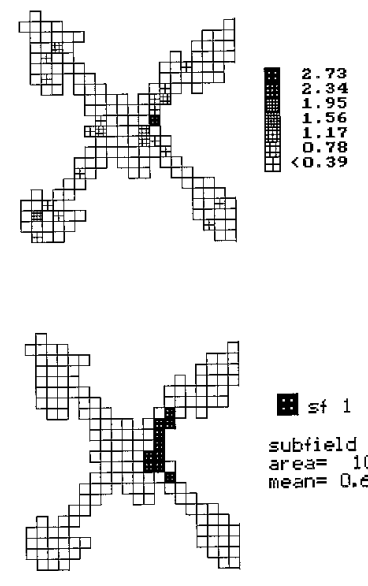

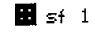

subfield 1 ares= $=10$
hes
D

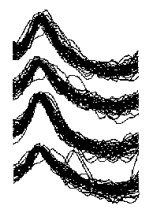

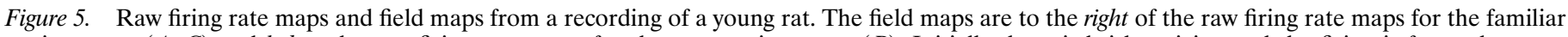

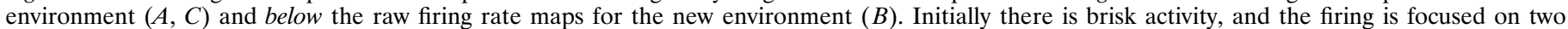

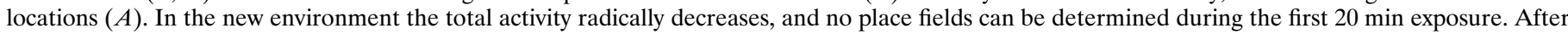

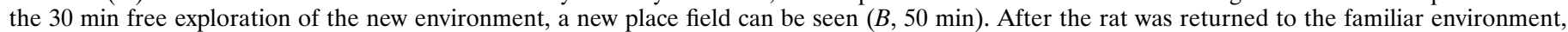

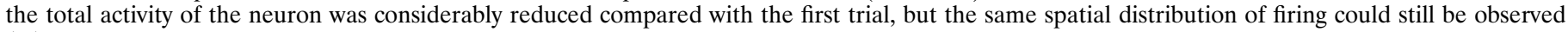
$(C)$. $D$, Waveform of the neuron as recorded with four tips of the tetrode.

ronment trials. Aged memory-impaired rats showed greater spatial selectivity in the familiar than in the new environment, whereas the young and aged memory-intact rats had the opposite pattern [repeated measures ANOVA, $F_{(2,38)}=5.64 ; p<0.01$ on the group $\times$ environment interaction; Fig. 6]. Conversely, the stability of the new place fields was weaker in the young rats $(r=$ 0.22 ) than the aged rats (memory-intact, $r=0.47$; memoryimpaired, $r=0.54$ ), as reflected by a significant difference among the experimental groups in the average cross-correlations over the five new environment recordings [ANOVA, $F_{(2,47)}=7.41 ; p<$ 0.005]. This finding is mainly attributed to those neurons in young rats that developed a place field only after $30 \mathrm{~min}$ in the new environment (Fig. 5).

\section{DISCUSSION}

The present experiment demonstrates that aging fundamentally alters the nature of hippocampal information processing of novel environmental cues. Whereas in young rats spatial representations were consistently created anew when the environment was changed, in aged rats place fields often maintained similar patterns across the two environments. Furthermore, spatial selectivity of place fields was decreased in the new environment only in aged memory-impaired rats.

To date, few studies have characterized the firing patterns of place cells during the exposure to a new environment. Hill (1978) reported that most place cells demonstrate considerable spatial selectivity even during their first visit to the place field location in a new environment. Later studies have shown that although spatially selective firing can be observed as soon as the rat enters an unexplored environment, the place fields require at least 10-30 min and up to $4 \mathrm{hr}$ of exploration to focus maximally (Austin et al., 1993; Wilson and McNaughton, 1993). In the present study some cells showed well demarcated place fields during the first 5 min of exploration of the new environment, whereas other cells needed an exposure of more than $30 \mathrm{~min}$ to build up distinct place fields. Nevertheless, some degree of focusing with repeated exposures to the environment was evident in all place fields of both young and old rats.

It has been suggested that place fields are initially based on path integration operations in which motor feedback is important (McNaughton et al., 1996), and only later do the fields become anchored to distal landmarks, resulting in increased spatial selectivity. Our findings are consistent with this notion, at least for aged rats. It has been shown that alterations in task requirements or maze restrictions that change the trajectories of the rat can dramatically change the place fields, even though the surrounding environment is kept the same (Markus et al., 1995). The present results suggest that the reverse may also be true; in this study the constant physical dimensions of the maze may have restricted path integration and, consequently, may have kept constant some aspects of the spatial representations across the two environments. However, this seemed to be the case only for the aged rats, because the place fields of young rats all showed qualitative 


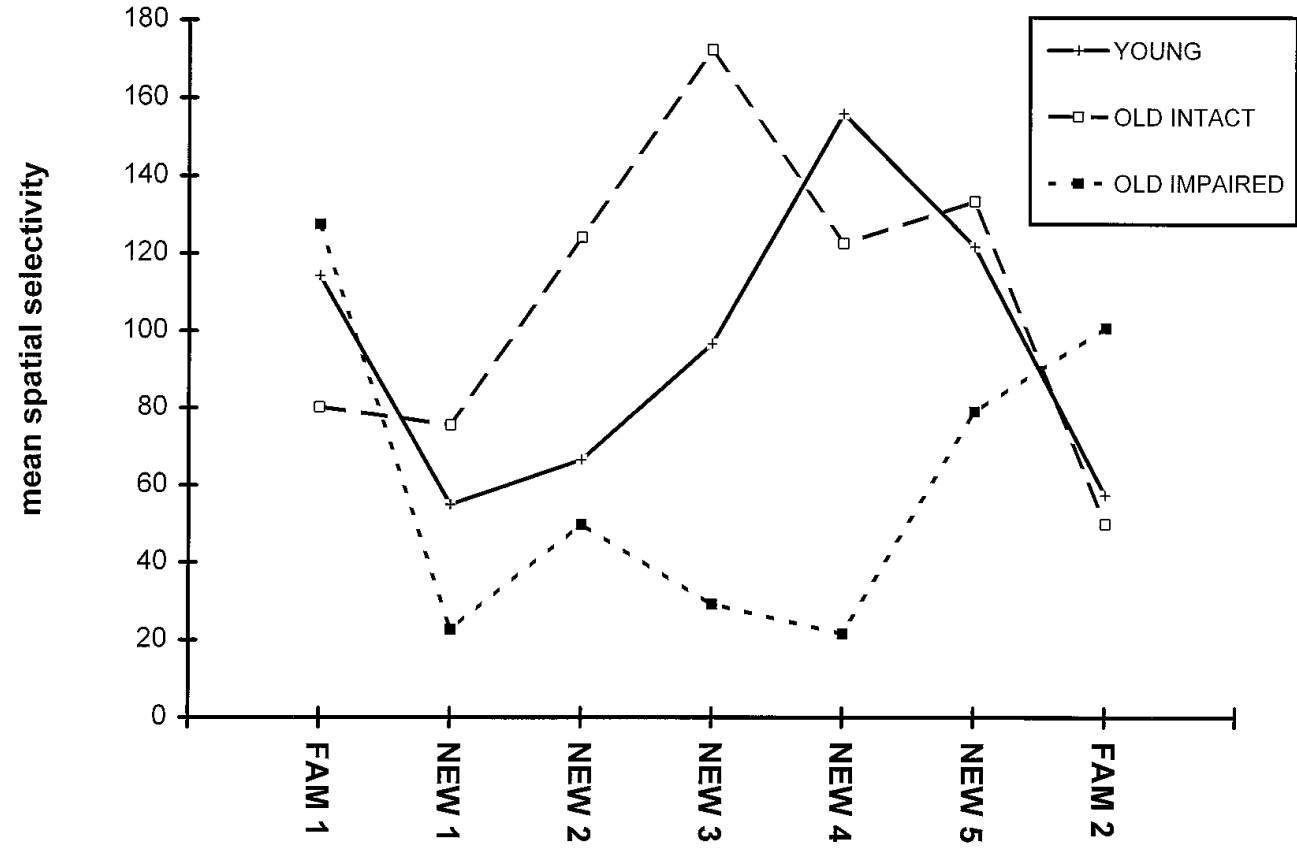

Figure 6. Mean spatial selectivity of all neurons in the three experimental groups. The spatial selectivity decreased in all groups during the first $5 \mathrm{~min}$ trial in the new environment ( $N E W 1)$. In young and aged memory-intact rats the spatial selectivity increased above the initial level within $20 \mathrm{~min}$ of exposure to the new environment. In the aged memoryimpaired rats spatial selectivity in the new environment remained low until they were given a $30 \mathrm{~min}$ free exploration time (between $N E W 4$ and $N E W 5$ ). Note the drop of spatial selectivity in young and aged intact animals after return to the familiar environment (FAM 2), which is in contrast with the further increase in spatial selectivity in aged memory-impaired rats. changes. The aged rats seem to be path integrators, whereas the young rats integrate views of the entire cue configuration across time. This accounting is in agreement with behavioral observations indicating that aged rats tend to use "response" strategies in solving maze tasks, whereas young animals use "spatial" strategies (Barnes et al., 1980).

The present indications of diminished place field plasticity are also in agreement with findings presented in our accompanying paper on the effect of cue manipulations on place fields in young and aged animals (Tanila et al., 1997). When distal and local cues were rotated repeatedly in opposite directions (double rotation), the place cells of young animals gradually developed new spatial representations for the altered cue configurations. By contrast, place cells in aged memory-impaired rats almost always followed the distal cues. It is possible that the prominent landmark in our new environment resembled one of the four landmarks in the familiar environment, and the aged rats oriented accordingly. Alternatively, the aged rats may have recognized the radial arm maze the same despite the altered surfaces that covered the arms. When distal cues were scrambled in our accompanying study (Tanila et al., 1997) the aged memory-impaired rats often followed the local cues that they ignored during double rotation. It is possible that change of the distal cues in the present study made the aged rats pay attention to the maze itself. In other words, aged rats may have found sufficient similarity between the two environments to treat them the same, and consequently, the place fields might have maintained their original shapes and relative locations with respect to the maze, even though the fields usually rotated. Possibly the mismatch between the two environments may have caused the spatial selectivity of the place fields to decrease. It is also possible that in the young rats some hippocampal cells represent simple prominent features of the environment and thus build up place fields almost instantly in a new environment, whereas others code for more complex relationships between environmental cues and thus require more time to build up.

The finding that memory-impaired aged rats did not show silent cells in any environment suggests that these aged rats have defective inhibitory processes in their hippocampal cir- cuitry. This is in agreement with a recent finding of a severe loss of calbindin-immunoreactive interneurons in CA1 with age (Potier et al., 1994). Another possible explanation for the absence of silent pyramidal cells is more diffuse spread of excitation because of overlapping inputs to individual cells or through gap junctions, which appear in higher density in aged rats that in young ones (Barnes et al., 1987). One additional explanation for the absence of silent cells in either of the environments is that the aged memory-impaired rats found some common features across the environments, resulting in activation of the cells in both environments. It is possible that in more radically different environments some silent cells could have been found even in these rats.

The second major finding of the present study was that the spatial selectivity of place cells in the new environment decreased in association with age and spatial learning ability. It is remarkable that the spatial selectivity of complex spike cells in aged memoryimpaired rats was higher than in young rats when they were tested in the familiar environment. The decrease in spatial selectivity in memory-impaired aged rats was attributable to decreased spatial selectivity of not only fields that appeared in the new environment but also fields that were retained across environments. This seems to contrast the results of our accompanying paper on the effect of cue manipulations on place fields in young and aged animals (Tanila et al., 1997). In that study the spatial selectivity of aged memory-impaired rats did not decrease when they were exposed to an environment in which the familiar cues were rearranged. However, these conflicts can be easily understood by the models of path integration (McNaughton et al., 1996) and pattern completion (Rolls, 1990). If we assume that the aged animals used only one or two of the available distal cues as landmarks, they could easily maintain the integrity and spatial selectivity of their hippocampal place fields as long as these cues were present in the environment, even though in a different context. These cues that they remembered and paid attention to determined the gross orientation of the fields, and through pattern completion the entire representation then could be activated. By contrast, in the new environment none of the familiar cues were present; thus 
some error on the spatial signal based on path integration alone would be expected. This parallels the observation that the spatial selectivity of place fields in a familiar environment is diminished when the lights are turned off (Markus et al., 1994).

Our finding of decreased spatial selectivity of place fields in a new environment parallels observations from behavioral studies showing that some aged animals are clearly impaired in their spatial learning, but they eventually succeed in the task, and their ultimate performance is guided by the spatial relations among cues (Barnes, 1988; DeToledo-Morrell et al., 1988; Gage et al., 1988; Gallagher and Nicolle, 1993). The results of the present study suggest that the spatial selectivity of hippocampal place fields may be a useful measure of the effectiveness of spatial encoding. However, this measure should be determined during the course of learning details and relationships about the environment rather than after learning is complete.

\section{REFERENCES}

Austin KB, White LH, Shapiro ML (1993) Short- and long-term effects of experience on hippocampal place fields. Soc Neurosci Abstr 19:797.

Barnes CA (1988) Aging and the physiology of spatial memory. Neurobiol Aging 9:563-568.

Barnes CA (1994) Normal aging: regionally specific changes in hippocampal synaptic transmission. Trends Neurosci 17:13-18.

Barnes CA, Nadel L, Honig WK (1980) Spatial memory deficit in senescent rats. Can J Psychol 34:29-39.

Barnes CA, McNaughton BL, O'Keefe J (1983) Loss of place specificity in hippocampal complex spike cells of senescent rat. Neurobiol Aging 4:113-119.

Barnes CA, Rao G, McNaughton BL (1987) Increased electrotonic coupling in aged rat hippocampus: a possible mechanism for cellular excitability changes. J Comp Neurol 259:549-558.

DeToledo-Morrell L, Geinisman Y, Morrell F (1988) Age-dependent alterations in hippocampal synaptic plasticity: relation to memory disorders. Neurobiol Aging 9:581-590.

Foster TC, Castro CA, McNaughton BL (1989) Spatial selectivity of rat hippocampal neurons: dependence on preparedness for movement. Science 244:1580-1582.

Gage FH, Chen KS, Buzsaki G, Armstrong D (1988) Experimental approaches to age-related cognitive impairments. Neurobiol Aging 9:645-655.

Gallagher M, Nicolle MM (1993) Animal models of normal aging: relationship between cognitive decline and markers in hippocampal circuitry. Behav Brain Res 57:155-162.

Gallagher M, Burwell R, Burchinal M (1993) Severity of spatial learning impairment in aging: development of a learning index for performance in the Morris water maze. Behav Neurosci 107:618-626.
Hill AJ (1978) First occurrence of hippocampal spatial firing in a new environment. Exp Neurol 62:282-297.

Markowska AL, Stone WS, Ingram DK, Reynolds J, Gold PE, Conti LH, Pontecorvo MJ, Wenk GL, Olton DS (1989) Individual differences in aging: behavioral and neurobiological correlates. Neurobiol Aging 10:31-43.

Markus EJ, Barnes CA, McNaughton BL, Gladden VL, Skaggs WE (1994) Spatial information content and reliability of hippocampal CA1 neurons: effects of visual input. Hippocampus 4:410-421.

Markus EJ, Qin YL, Leonard B, Skaggs WE, McNaughton BL, Barnes CA (1995) Interactions between location and task affect the spatial and directional firing of hippocampal neurons. J Neurosci 15: 7079-7094.

McNaughton BL, Barnes CA, Gerrard JL, Gothard K, Jung MW, Knierim JJ, Kudrimoti H, Qin Y, Skaggs WE, Suster M, Weaver KL (1996) Deciphering the hippocampal polyglot: the hippocampus as a path integration system. J Exp Biol 199:173-185.

Mizumori SJY, Lavoie AM, Kalyani A (1996) Redistribution of spatial representation in the hippocampus of aged rats performing a spatial memory task. Behav Neurosci 110:1006-1016.

Morris RG, Garrud P, Rawlins JN, O'Keefe J (1982) Place navigation impaired in rats with hippocampal lesions. Nature 297:681-683.

O'Keefe J, Conway DH (1978) Hippocampal place units in the freely moving rat: why they fire where they fire. Exp Brain Res 31:573-590.

Potier B, Krzywkowski P, Lamour Y, Dutar P (1994) Loss of calbindinimmunoreactivity in CA1 hippocampal stratum radiatum and stratum lacunosum-moleculare interneurons in the aged rat. Brain Res 661:181-188.

Ranck JB Jr (1973) Studies on single neurons in dorsal hippocampal formation and septum in unrestrained rats. I. Behavioral correlates and firing repertoires. Exp Neurol 41:461-531.

Rapp PR, Amaral DG (1992) Individual differences in the cognitive and neurobiological consequences of normal aging. Trends Neurosci 15:340-344.

Rapp PR, Heindel WC (1994) Memory systems in normal and pathological aging. Curr Opin Neurol 7:294-298.

Rolls ET (1990) Functions of the primate hippocampus in spatial processing and memory. In: Neurobiology of comparative cognition (Kesner RP, Olton DS, eds), pp 339-362, Hillsdale, NJ: Lawrence Erlbaum Associates.

Spangler EL, Chachich ME, Curtis NJ, Ingram DK (1989) Age-related impairment in complex maze learning in rats: relationship to neophobia and cholinergic antagonism. Neurobiol Aging 10:133-141.

Tanila H, Shapiro ML, Gallagher M, Eichenbaum H (1997) Brain aging: changes in the nature of information coding by the hippocampus. J Neurosci 17:5155-5166.

Wiener SI, Paul CA, Eichenbaum H (1989) Spatial and behavioral correlates of hippocampal neuronal activity. J Neurosci 9:2737-2763.

Wilson MA, McNaughton BL (1993) Dynamics of the hippocampal ensemble code for space. Science 261:1055-1058. 